\title{
Do bupivacaine, clindamycin, and gentamicin at their clinical concentrations enhance rocuronium-induced neuromuscular block?
}

\author{
Soo-Il Lee, Ji Hyeon Lee, Sang Yoong Park, and Jae-Won Park \\ Department of Anesthesiology and Pain Medicine, Dong-A University Medical College, Busan, Korea
}

Background: Bupivacaine, clindamycin, and gentamicin inhibit neuromuscular (NM) conduction. When they are combined, they may synergistically reduce the effective concentration of each to the therapeutic concentration in augmenting rocuronium-induced NM block. Thus, the aim of this study was to investigate whether combinations of the three drugs, at around their therapeutic concentrations, potentiate rocuronium-induced NM block.

Methods: Fifty-seven left-phrenic nerve hemidiaphragms (Male S-D rats, 150-250 g) were hung in a 20-ml organ bath filled with Krebs solution. Three consecutive single-twitch tensions $(0.1 \mathrm{~Hz})$ and one tetanic tension $(50 \mathrm{~Hz}$ for $1.9 \mathrm{~s}$ ) were obtained. A Krebs solution was premixed with concentration sets of bupivacaine and clindamycin, bupivacaine and gentamicin, or bupivacaine, clindamycin and gentamicin. Then, the concentration of rocuronium was cumulatively increased in the Krebs solution $(1,3,5,7,9,12,14,16,18$, and $20 \mu \mathrm{M})$ until an $80 \%$ to $90 \%$ reduction in single twitch was attained. The effective concentrations for each experiment were determined with the probit model.

Results: The combinations of bupivacaine, clindamycin, and gentamicin enhanced rocuronium-induced NM block. When the three drugs were applied simultaneously, their concentrations were reduced to near-therapeutic levels in potentiating the action of rocuronium.

Conclusions: Bupivacaine, clindamycin, and gentamicin blocked NM conduction, and when all three drugs were applied together, they augmented rocuronium-induced NM block at their near-therapeutic concentrations. Clinicians should be aware of the cooperability in NM block between drugs that interrupt NM conduction. (Korean J Anesthesiol 2013; 64: 346-352)

Key Words: Bupivacaine, Clindamycin, Gentamicin, Neuromuscular block, Rocuronium, Therapeutic concentration.

Received: June 27, 2012. Revised: February 8, 2013. Accepted: February 15, 2013.

Corresponding author: Soo-Il Lee, M.D., Ph.D., Department of Anesthesiology and Pain Medicine, Dong-A University Medical College, Dong-A University Hospital, Daesingongwon-ro 26, Seo-gu, Busan 602-715, Korea. Tel: 82-51-240-5390, Fax: 82-51-247-7819, E-mail: silee@dau.ac.kr Presented in part at the 88th Meeting held by the Korean Society of Anesthesiologists, Seoul, Korea, November 3-5, 2011 at Grand Hilton.

(c) This is an open-access article distributed under the terms of the Creative Commons Attribution Non-Commercial License (http:// creativecommons.org/licenses/by-nc/3.0/), which permits unrestricted non-commercial use, distribution, and reproduction in any medium, provided the original work is properly cited. 


\section{Introduction}

Various drugs are administered simultaneously for anesthesia and surgery. When combined, such drugs may share a common adverse effect that is clinically insignificant when each drug is given separately. Local anesthetics can be used regionally or intravenously for perioperative pain control, and to prevent surgical site infection, antibiotics are administered before anesthesia [1]. In the perioperative period, some patients may receive combinations of therapeutic doses of the above drugs as well as a neuromuscular (NM) blocker. Unfortunately, these drugs all inhibit NM conduction.

Like other noncompetitive inhibitors, bupivacaine exerts its depressing action on acetylcholine receptors (AChRs) by reducing the amount of time that an ion channel is open without changing maximal agonist binding, and it precludes NM conduction [2]. Clindamycin produces an open ion channel block on AChRs in the end-plate [3] and decreases ACh release at the motor nerve terminal [4]. Thus, it prolongs or enhances NM block caused by nondepolarizing NM-blocking drugs (NMBD) [5]. Gentamicin acts like a calcium channel blocker, decreasing ACh release from the motor nerve terminal and depressing muscle contraction [6].

The potencies for single twitch (ST) inhibition are $50.3 \mu \mathrm{M}$ for bupivacaine [7], $24.6 \mathrm{mM}$ for clindamycin, and $1.3 \mathrm{mM}$ for gentamicin [8]. The potencies for an increase in tetanic fade (TF) are $11.4 \mu \mathrm{M}$ for bupivacaine [7], $9.9 \mathrm{mM}$ for clindamycin, and $1.45 \mathrm{mM}$ for gentamicin [8]. The potencies of the three drugs are far beyond their clinically therapeutic concentrations.

However, when they are administered together with rocuronium, they may synergistically interact to augment rocuronium-induced NM block at their clinical concentrations. If the combined administration of rocuronium, bupivacaine, clindamycin, and gentamicin were to occur in a patient perioperatively, this could trigger impairment in spontaneous ventilation, requiring prolonged assisted ventilation [9].

Thus, the aim of this study was to investigate whether combinations of the four drugs, at near-clinical concentrations, potentiate the rocuronium-induced NM block in rat phrenic nerve-hemidiaphragm preparations.

\section{Materials and Methods}

The Institutional Animal Care and Use Committee approved the experimental protocol. All experimental courses followed the Guide for the Care and Use of Laboratory Animals provided by the National Academy of Sciences. Fifty-seven male SpragueDawley rats (5-7 weeks in age and 150-250 g in weight) were anesthetized by a paravertebral injection of propofol ( $50 \mathrm{mg} / \mathrm{kg}$ ) at the lumbar level and then sacrificed. The phrenic nerve and diaphragm were excised together, and the left diaphragm was separated. Left phrenic nerve-hemidiaphragm preparations were hung in a 20-ml organ bath that was filled with Krebs solution (118 mM NaCl, $5 \mathrm{mM} \mathrm{KCl,} 2.5 \mathrm{mM} \mathrm{CaCl}_{2}, 30 \mathrm{mM}$ $\mathrm{NaHCO}_{3}, 1 \mathrm{mM} \mathrm{KH}_{2} \mathrm{PO}_{4}, 2.5 \mathrm{mM} \mathrm{MgSO}_{4}$ and $11 \mathrm{mM}$ glucose).

The bath solution was maintained at $32^{\circ} \mathrm{C}$ by continuously circulating heated water in the space between the double walls and aerating it with a gas mixture of $95 \%$ oxygen and $5 \%$ carbon dioxide. The $\mathrm{pH}$ of the solution was maintained at 7.38 to 7.42. Spent Krebs solution was exchanged with fresh solution at 10-minute intervals. The preparation was attached to a force transducer (Model 1030, UFI, Morro Bay, CA, USA) with a stainless steel wire and allowed to stabilize for another $20 \mathrm{~min}$, maintaining a phrenic nerve stimulation of $0.1 \mathrm{~Hz}$. The phrenic nerve, connected to an electrode, was stimulated with supramaximal square wave impulses of $200 \mu$ s in duration using an electrical stimulator (Model ML112, ADInstruments Pty Ltd, Bella Vista, NSW, Australia).

The diaphragm muscle was stretched until the maximum output tension was measured after stimulation, followed by another $10 \mathrm{~min}$ for stabilization. At every drug concentration, a period of 20 min was allowed to pass to establish a pseudosteady state between the solution and muscle tissue before tension measurements were made. Three consecutive ST tensions $(0.1 \mathrm{~Hz})$ and one tetanic tension ( $50 \mathrm{~Hz}$ for $1.9 \mathrm{~s}$ ) were obtained before the addition of each drug and at each change of drug concentration. These tensions were then digitized and stored on a Power Macintosh 7100 (Apple Computer Corp, Cupertino, CA, USA) using data acquisition software (MacLab, ADInstruments Pty Ltd, Bella Vista, NSW, Australia).

Krebs solutions were premixed as follows: for concentration sets of bupivacaine and clindamycin phosphate, 0.0 and $0.0(\mathrm{R}$ alone, $\mathrm{n}=5)$; 0.1 and $0.0(\mathrm{~B} 0.1, \mathrm{n}=5) ; 1.0$ and $0.0(\mathrm{~B} 1, \mathrm{n}=5)$; 1.0 and 50 (B1 C50, $\mathrm{n}=4$ ); 2.0 and 50 (B2 C50, $\mathrm{n}=3$ ); 0.1 and 250 (B0.1 C250, n = 3); and 1.0 and 250 (B1 C250, n = 5) $\mu \mathrm{M}$; for concentration sets of bupivacaine and gentamicin, 0.1 and 100 (B0.1 G100, $\mathrm{n}=5$ ); 0.1 and 50 (B0.1 G50, $\mathrm{n}=6$ ); 0.1 and 10 (B0.1 G10, $\mathrm{n}=4$ ) $\mu \mathrm{M}$; and for concentration sets of bupivacaine, clindamycin, and gentamicin, 1.0, 20, and 10 (B1 C20 G10, n = 4); 1.0, 10, and 5 (B1 C10 G5, n = 3); and 0.5, 10, and 5 (B0.5 $\mathrm{C} 10 \mathrm{G} 5, \mathrm{n}=5) \mu \mathrm{M}$. Then, the concentration of rocuronium was cumulatively increased in the Krebs solution $(1,3,5,7$, $9,12,14,16,18$, and $20 \mu \mathrm{M}$ ) until an $80 \%$ to $90 \%$ inhibition in ST was achieved. After data acquisition was completed, the drugs tested in the bath chamber were washed out with fresh Krebs solution, and an ST tension was recorded in a drug-free solution. Data from a preparation were analyzed only if the ST tension of the preparation returned to a value greater than $90 \%$ of the baseline.

Mean ST tension was calculated by averaging three con- 
secutive measurements. Peak tetanic tension (PTT) was measured at $0.2 \mathrm{~s}$ after the start of the tetanic stimulation for an ascending tetanic tension or at the peak point for a fading tetanic tension. The effect of the drugs on ST, PTT, and TF was presented as a percent reduction of the baseline for ST or PTT and as a normalized percent increase of TF $(=100 \times(1-[100$ - \%increase of TF] / [100 - \%increase of TF in baseline])) [8]. The effective concentrations (EC) of rocuronium for ST and TF were determined by the probit model, and the concentrationresponse curves of rocuronium for ST and TF were plotted.

The $\mathrm{EC}_{50} \mathrm{~s}$ of rocuronium given at different concentration sets were compared using the Student's t-test with Bonferroni's correction to adjust the significance level. Differences were considered significant when $\mathrm{P}<0.05$.

\section{Results}

Based on the concentration-response (C-R) curves of rocuronium for bupivacaine and clindamycin (Fig. 1), to reduce ST, 1 $\mu \mathrm{M}$ or $2 \mu \mathrm{M}$ bupivacaine increased the potency of rocuronium, and the combination of $250 \mu \mathrm{M}$ clindamycin and $0.1 \mu \mathrm{M}$ or $1 \mu \mathrm{M}$ bupivacaine shifted the C-R curves of rocuronium to the left (Fig. 1A). To inhibit ST, the potency of rocuronium in combination with $1 \mu \mathrm{M}$ bupivacaine and $250 \mu \mathrm{M}$ clindamycin was stronger than the combination of $2 \mu \mathrm{M}$ bupivacaine and $50 \mu \mathrm{M}$ clindamycin (Fig. 1A). To increase the TF, 1 or $2 \mu \mathrm{M}$ bupivacaine and the combination of $0.1 \mu \mathrm{M}$ bupivacaine and
$250 \mu \mathrm{M}$ clindamycin increased the potency of rocuronium (Fig. 1B). Unexpectedly, to increase the TF, the combination of $1 \mu \mathrm{M}$ bupivacaine and $250 \mu \mathrm{M}$ clindamycin had a similar effect on the potency of rocuronium to that of $1 \mu \mathrm{M}$ bupivacaine (Fig. 1B). For the ST and TF, clindamycin at a concentration of $50 \mu \mathrm{M}$ failed to move the C-R curve of rocuronium to the left (Fig. 1A and $\mathrm{B}$ ).

Based on the $\mathrm{C}-\mathrm{R}$ curves of rocuronium in $0.1 \mu \mathrm{M}$ bupivacaine and gentamicin (Fig. 2), to depress ST, 50 or 100 $\mu \mathrm{M}$ gentamicin shifted the C-R curve of rocuronium to the left (Fig. 2A), and to augment TF, $100 \mu \mathrm{M}$ gentamicin shifted the C-R curve to the left (Fig. 2B). Bupivacaine at the concentration of $0.1 \mu \mathrm{M}$ failed to move the C-R curve of rocuronium (Fig. 2A, and $\mathrm{B})$.

Based on the C-R curves of rocuronium for bupivacaine, clindamycin, and gentamicin (Fig. 3), to inhibit ST, the combination of $1 \mu \mathrm{M}$ bupivacaine, $20 \mu \mathrm{M}$ clindamycin, and 10 $\mu \mathrm{M}$ gentamicin caused a larger decrease in the $\mathrm{EC}_{50}$ (half maximal effective concentration) of rocuronium than that caused by $1 \mu \mathrm{M}$ bupivacaine alone (Fig. 3A). To enhance TF, all combinations of bupivacaine, clindamycin, and gentamicin caused a larger decrease in the $\mathrm{EC}_{50}$ of rocuronium than that caused by $1 \mu \mathrm{M}$ bupivacaine alone (Fig. 3B).

When measured for the same combination set, the specific EC of rocuronium that reduces ST was greater than the specific EC that increases TF.

\section{A}

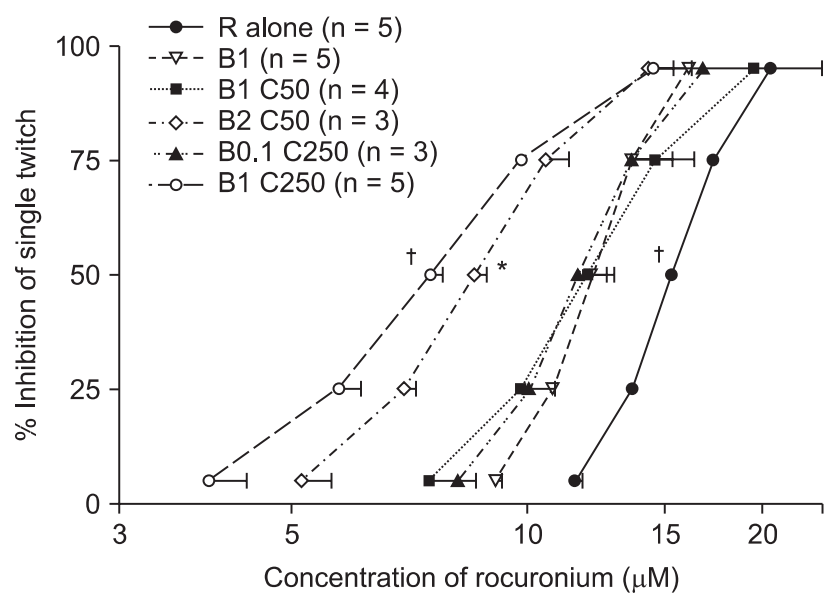

B

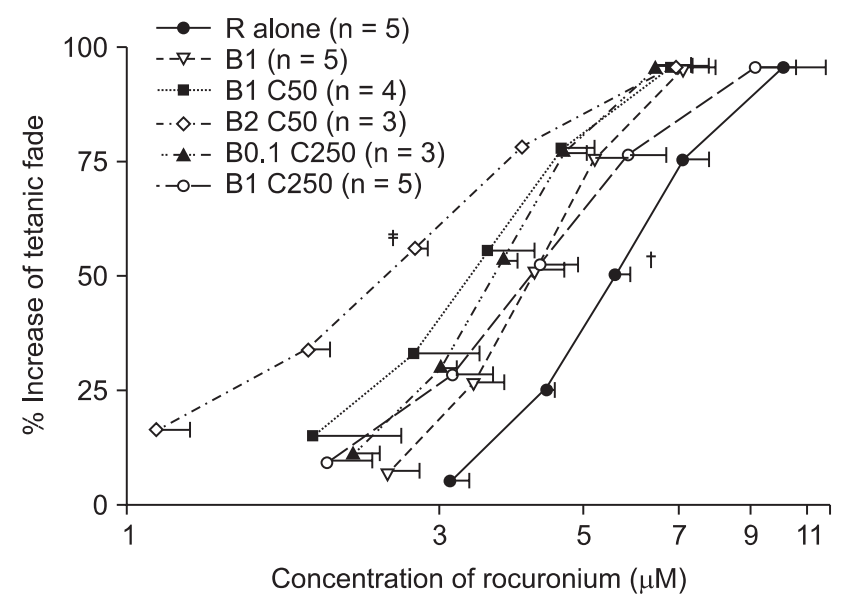

Fig. 1. Based on the cumulative concentration-effect curves for rocuronium on a single twitch at $0.1 \mathrm{~Hz}$ (A) and tetanic fade at $50 \mathrm{~Hz}$ for 1.9 seconds (B), bupivacaine, and clindamycin shift curves to the left; hence, the two drugs augment the potency of rocuronium. Unexpectedly, for increasing TF, the set of bupivacaine one $\mu \mathrm{M}$, and clindamycin $250 \mu \mathrm{M}$ has the potency of rocuronium similar to that by one $\mu \mathrm{M}$ bupivacaine (B), but for reducing ST, has the greatest potency of rocuronium (A). The numbers next to B and C are the concentrations of bupivacaine and clindamycin, and the unit of concentrations for bupivacaine and clindamycin is $\mu \mathrm{M}$. The scale of ordinate presents percentage, and that of abscissa, $\log$ (concentration). The values of concentrations are mean \pm SD. B, C and R represent bupivacaine, clindamycin, and rocuronium. *Indicates $\mathrm{P}<0.05$, vs all the rest sets except $\mathrm{B} 0.1 \mathrm{C} 250,{ }^{\dagger}$ indicates $\mathrm{P}<0.05$, vs all the rest sets, and ${ }^{\ddagger}$ indicates $\mathrm{P}<0.05$, vs $\mathrm{B} 0.1 \mathrm{C} 250, \mathrm{~B} 1$, and $\mathrm{R}$ alone. 
A

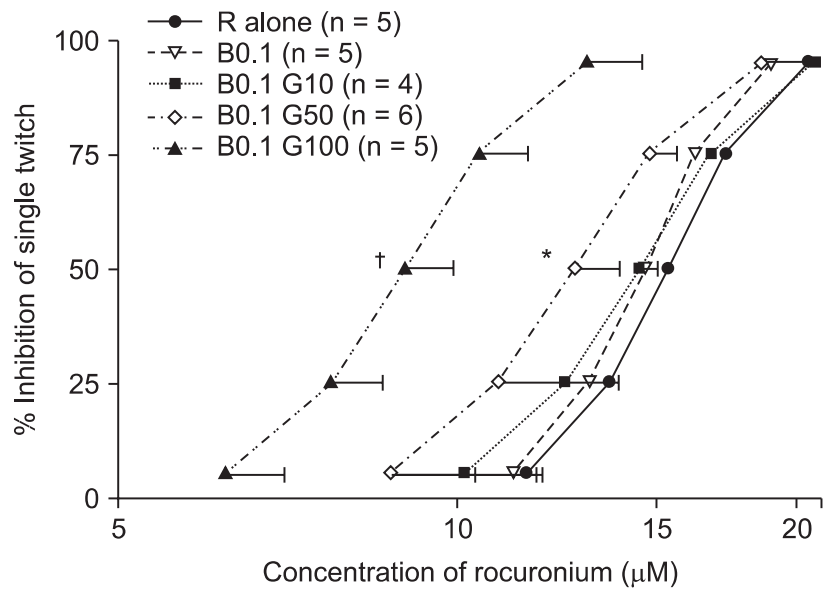

B

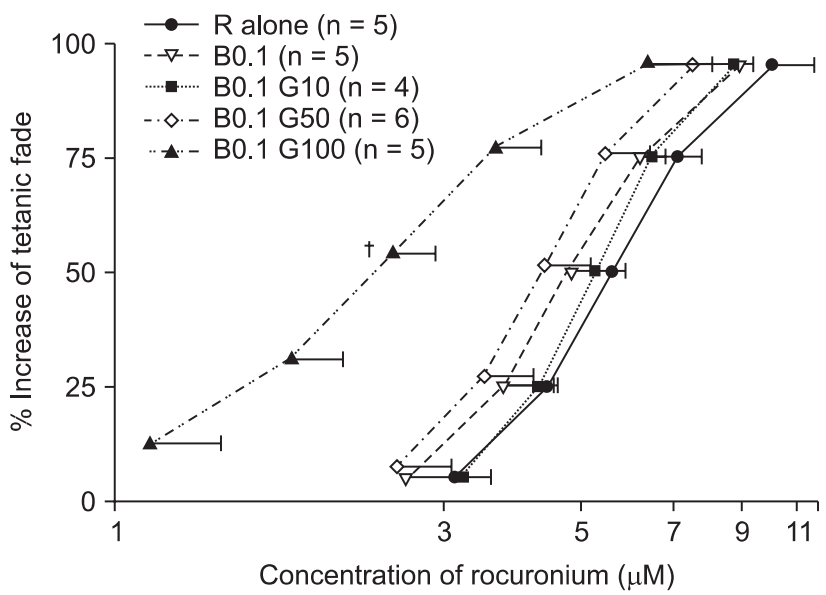

Fig. 2. Based on the cumulative concentration-effect curves for rocuronium on a single twitch at $0.1 \mathrm{~Hz}$ (A) and tetanic fade at $50 \mathrm{~Hz}$ for 1.9 seconds (B), bupivacaine and gentamicin shift curves to the left; hence, the two drugs augment the potency of rocuronium. The numbers next to $\mathrm{B}$ and $\mathrm{G}$ are the concentrations of bupivacaine and gentamicin, and the unit of concentrations for bupivacaine, and gentamicin is $\mu \mathrm{M}$. The scale of ordinate presents percentage, and that of abscissa, $\log$ (concentration). The values of concentration are mean \pm SD. B, G and R represent bupivacaine, gentamicin, and rocuronium. *Indicates $\mathrm{P}<0.05$, vs $\mathrm{R}$ alone, and ${ }^{\dagger}$ indicates $\mathrm{P}<0.05$, vs all the rest sets.

A

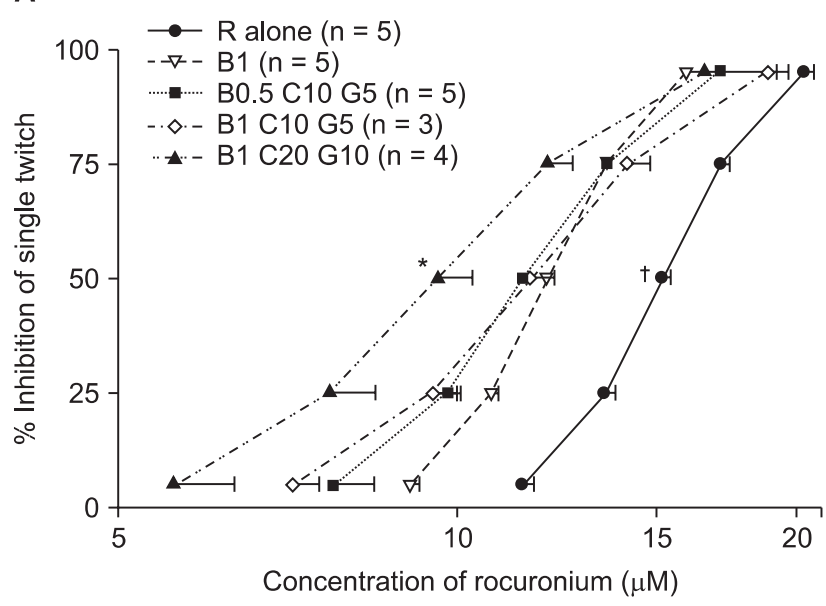

B

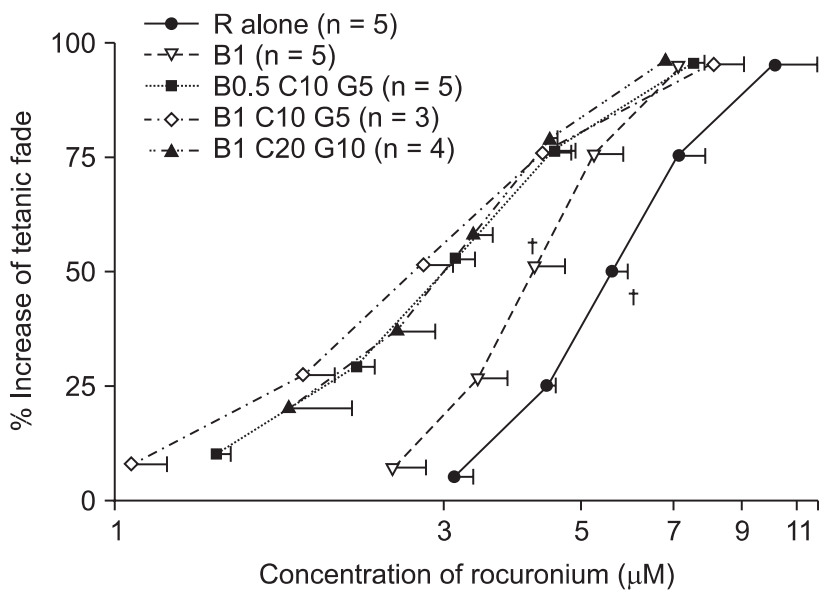

Fig. 3. Based on the cumulative concentration-effect curves for rocuronium on single twitch at $0.1 \mathrm{~Hz}(\mathrm{~A})$ and tetanic fade at $50 \mathrm{~Hz}$ for 1.9 seconds (B), bupivacaine, clindamycin, and gentamicin shift curves to the left; hence, the three drugs augment the potency of rocuronium. The numbers next to B C and $\mathrm{G}$ are the concentrations of bupivacaine, clindamycin and gentamicin, and the unit of concentrations for bupivacaine, clindamycin, and gentamicin is $\mu \mathrm{M}$. The scale of ordinate presents percentage, and that of abscissa, log (concentration). The values of concentrations are mean \pm SD. B, C, G and R represent bupivacaine, gentamicin and rocuronium. *indicates $\mathrm{P}<0.05$, vs all the rest sets except $\mathrm{B} 1 \mathrm{C} 10 \mathrm{G} 5$, and ${ }^{\dagger}$ indicates $\mathrm{P}<0.05$, vs all the rest sets.

\section{Discussion}

Several types of electrical stimulations to motor nerves are used to evaluate the neuromuscular pharmacology of drugs: ST, tetanic, and Train Of Four stimulations. Each type brings different mechanisms into operation for the conducting NM junction. Thus, the modification of muscle contraction caused by a mode of electrical stimulation suggests that some intervention must modify some mechanism in NM conduction. Therefore, it is worthwhile to investigate which mechanism is involved in reducing ST and PTT or increasing TF.

A certain amount of acetylcholine (ACh) from the motor nerve end is released by ST stimulation and binds AChRs in the endplate [10], eliciting a single muscle contraction called ST. From this, the inhibition of ST can be produced pre- or postsynaptically, as follows: decrease the store of readily releasable ACh and decrease the secretion of ACh in the active zones, followed by the occlusion and desensitization of AChRs [10]. 
Tetanic stimulation causes ACh to accumulate in the synaptic cleft; the accumulated AChs act on presynaptic ACh receptors in a positive feedback manner [11] and increase intracellular calcium ion concentration $\left(\left[\mathrm{Ca}^{2+}\right]_{\mathrm{i}}\right)$ at the motor nerve end. Finally, increased $\left[\mathrm{Ca}^{2+}\right]_{\mathrm{i}}$ enhances the synthesis of ACh $[10,12]$. Normally, tetanic stimulation produces an ascending tetanic contraction. An ascending tension consists of two components: early secretion of ACh from a store of readily releasable ACh in the active zones [10] and an ensuing secretion of ACh from the mobilization of AChs [13].

The rapid decay in the amplitude of the first 10 end-plate potentials seen in the beginning of a tetanus can be ascribed to the decrease in the store of readily releasable AChs in the active zones [14]. According to this finding, the early part of the tetanic tension (about 10 impulses [0.2 s] in $50 \mathrm{~Hz}$ of tetanic stimulation) would be equivalent to a tension, which is produced by ACh released from a store of readily releasable AChs. Therefore, we measured a tension either at $0.2 \mathrm{~s}$ after tetanic stimulation for an ascending tetanic tension or at a peak point within $0.2 \mathrm{~s}$ for an unsustained one; we termed this peak point PTT. Accordingly, the inhibition by an NM blocker of PTT may be associated with a presynaptic reduction in the store of readily releasable AChs in the active zones. Moreover, because ACh should bind AChR to cause tetanic tension, the inhibition of PTT may also be relevant to the number of available AChRs postsynaptically.

A tetanic stimulation mobilizes the preformed acetylcholines that attach as vesicles at the skeletons in the nerve endings and enhances the synthesis and mobilization of new AChs [10]. The ensuing release of ACh maintains the later part of the tetanic tension during a tetanic stimulation [13]. Unlike an ascending tetanic tension, a tetanic tension can descend its amplitude during a tetanus after applying an NM blocker. The descending tension is termed TF. Possible mechanisms of TF include depressing ACh mobilization during tetanic stimulation [11], reducing the mean length of time that the AChR-ion channel complex is open by blocking the open ion channels $[2,15]$, and decreasing the available AChRs by occlusion and desensitization [16].

In this study, $0.1 \mu \mathrm{M}$ bupivacaine failed to augment the potency of rocuronium, but 1 or $2 \mu \mathrm{M}$ bupivacaine did augment it. The mechanism of bupivacaine may be that it inhibits the ion channel of AChR from opening [17], multiplies the inactive form of AChR [2], reduces the mean length of time that the ion channel of AChR is open [15], or depresses ACh synthesis presynaptically [18]. In addition, bupivacaine has been shown to potentiate vecuronium-induced NM blockade [19]. Finally, 1 or $2 \mu \mathrm{M}$ bupivacaine seems to potentiate rocuronium-induced NM block.

From the combination of bupivacaine and clindamycin, 50 $\mu \mathrm{M}$ clindamycin had no significant effect on NMB caused by rocuronium, but $250 \mu \mathrm{M}$ clindamycin had significant effects. Clindamycin $[3,4]$ presynaptically reduces the quantal content of the end-plate potential and postsynaptically blocks the open state of the end-plate ion channel of AChR. In terms of clinical characteristics, case studies have reported profound clindamycin-induced NMB [20], and clindamycin creates a prolonged blockade of non-depolarizing muscle relaxants [5]. Based on this study's finding that the effect of clindamycin on rocuronium occurred in the presence of bupivacaine, clindamycin inhibits NM conduction.

The combination of $1 \mu \mathrm{M}$ bupivacaine and $250 \mu \mathrm{M}$ clindamycin shifted the C-R curve for TF to a lesser degree than the C-R curve for ST. In other words, they augment the rocuroniuminduced inhibition of ST, as well as the rocuronium-induced increase of TF, although to a lesser extent. The reason for this phenomenon may be unknown. In fact, at low concentrations, bupivacaine or clindamycin enhance ST $[7,21]$. Because the potency of rocuronium for TF is greater than that for ST [7], rocuronium at high concentrations for ST may depress the enhancement by bupivacaine and clindamycin to a greater extent compared with rocuronium at low concentrations for TF. This issue requires further investigation.

From the combination of $0.1 \mu \mathrm{M}$ bupivacaine and gentamicin, rocuronium-induced NMB was enhanced with increasing concentrations of gentamicin. Gentamicin-induced NMB results from blocking the voltage-dependent calcium channels and decreasing the release of Ach at the motor nerve terminal [6]. Gentamicin reduces the end-plate potential [22], potentiates non-depolarizing NM blockers [23], and worsens symptoms of myasthenia gravis [24]. Therefore, gentamicin seems to interrupt NM conduction.

In a mixture of bupivacaine with $50 \mu \mathrm{M}$ clindamycin or 10 $\mu \mathrm{M}$ gentamicin, the clindamycin or the gentamicin fails to increase the potency of rocuronium. Together, the 3 drugs at doses of $1 \mu \mathrm{M}$ bupivacaine, $20 \mu \mathrm{M}$ clindamycin, and $10 \mu \mathrm{M}$ gentamicin move the $\mathrm{C}$ - $\mathrm{R}$ curves of rocuronium to the left of those for $1 \mu \mathrm{M}$ bupivacaine alone. The more drugs that are applied, the lower their concentrations become in increasing the potency of rocuronium. This finding seems to suggest synergistic interactions between the drugs.

The situation that arises when drugs do not share receptorsthat is, do not interfere with each other-is called mutual nonexclusivity. Mutually nonexclusive drugs form intrinsic synergistic effects [25]. The four drugs examined here, including rocuronium, may act on different sites in the AChR ion channel complex and have different mechanisms for blocking NM connection. Bupivacaine inhibits the ion channel of AChR from opening; clindamycin blocks the end-plate ion channel of AChR; gentamicin blocks the voltage-dependent calcium channels at the motor nerve terminal; and rocuronium binds 
AChR presynaptically and postsynaptically. Thus, as more drugs become involved in modifying NM conduction, they reduce each other's concentrations to a lower extent

With regard to therapeutic concentration and protein binding, the maximal therapeutic concentration of gentamicin or clindamycin is $12 \mu \mathrm{g} / \mathrm{ml}(\fallingdotseq 21 \mu \mathrm{M})$ or $17 \mu \mathrm{g} / \mathrm{ml}(\fallingdotseq 34 \mu \mathrm{M})$, respectively [22]. The percent protein binding of gentamicin is low and likely has negligible clinical significance [26]; based on this fact, the concentration of unbound gentamicin is close to the plasma concentration. The mean protein binding of clindamycin increased from $62.4 \%$ at $10 \mu \mathrm{g} / \mathrm{ml}$ to $81.2 \%$ at $2 \mu \mathrm{g} /$ $\mathrm{ml}$ [27], and, thus, the concentration of unbound clindamycin may be at least $40 \%$ within the concentrations studied. In a study on continuous epidural infusion of bupivacaine with an infusion rate of $25 \mathrm{mg} / \mathrm{h}$, a maximum plasma concentration of $0.9 \mathrm{mg} / \mathrm{L}(2.8 \mu \mathrm{M})$ was reached at the end of the infusion [28]. The free fraction for bupivacaine was $4.8 \%$, independent of the dose [28], and the maximum concentration of free bupivacaine, thus, was $0.14 \mu \mathrm{M}$.

The $\mathrm{EC}_{50}$ of rocuronium for ST is approximately $1 \mu \mathrm{M}$ in the adductor pollicis of patients. The potency in the diaphragm is about 2 times lower than that in the adductor pollicis in a human study and, thus, may be approximately $2 \mu \mathrm{M}$ rocuronium. The $\mathrm{EC}_{50} \mathrm{~s}$ of rocuronium for ST and TF are $15.4 \mu \mathrm{M}$ and $5.9 \mu \mathrm{M}$ in the rat diaphragm, respectively. The $\mathrm{EC}_{50}$ in the diaphragm for ventilation may be lower because ventilation is a tetanic contraction [29]. Airway muscles involved in protecting the airway against obstruction, aspiration, or both are the most susceptible to muscle relaxants [30]; recovery of ventilation cannot guarantee the ability of airway protection. It is likely that the $\mathrm{EC}_{50}$ in muscles that protect the airway is less than $1 \mu \mathrm{M}$ rocuronium, and the maintenance of airway patency requires the sustained tensions of the muscles. Therefore, the $\mathrm{EC}_{50}$ of rocuronium for airway patency may be lower. Moreover, the other NM blockers studied here, at their unbound therapeutic concentrations, may further reduce the $\mathrm{EC}_{50}$ of rocuronium for airway muscles.

TF indicates the ratio of end tetanic tension (ETT) to PTT and, thus, fails to represent accurately the variation in ACh mobilization in the nerve terminal. However, ETT appears to determine the amount of ACh synthesis more directly. Therefore, it seems natural that TF should be used to show the presence of an NM blocker. From this point of view, we recommend that PTT and ETT be used to determine the variation in the stores of readily releasable AChs in the active zones, as well as ACh synthesis for replenishing new AChs.

In conclusion, bupivacaine, clindamycin, and gentamicin have in common an NM-blocking action; when these drugs are applied simultaneously, they augment rocuronium-induced NM block at their near-therapeutic concentrations. Clinicians should be aware of the cooperativity in NM block between drugs that interrupt the NM conduction.

\section{Acknowledgments}

This work was supported by the Dong-A University research fund.

\section{References}

1. Kujath P, Bouchard R, Scheele J, Esnaashari H. Current perioperative antibiotic prophylaxis. Chirurg 2006; 77: 490, 492-8.

2. Arias HR, Blanton MP. Molecular and physicochemical aspects of local anesthetics acting on nicotinic acetylcholine receptorcontaining membranes. Mini Rev Med Chem 2002; 2: 385-410.

3. Prior C, Fiekers JF, Henderson F, Dempster J, Marshall IG, Parsons RL. End-plate ion channel block produced by lincosamide antibiotics and their chemical analogs. J Pharmacol Exp Ther 1990; 255: 1170-6.

4. Singh YN, Marshall IG, Harvey AL. Pre- and postjunctional blocking effects of aminoglycoside, polymyxin, tetracycline and lincosamide antibiotics. Br J Anaesth 1982; 54: 1295-306.

5. Sloan PA, Rasul M. Prolongation of rapacuronium neuromuscular blockade by clindamycin and magnesium. Anesth Analg 2002; 94: 123-4.

6. Parsons TD, Obaid AL, Salzberg BM. Aminoglycoside antibiotics block voltage-dependent calcium channels in intact vertebrate nerve terminals. J Gen Physiol 1992; 99: 491-504.

7. Lee JH, Lee SI, Lee SC, Choi SR, Rhee WJ. At therapeutic concentration bupivacaine causes neuromuscular blockade and enhances rocuronium-induced blockade. Korean J Anesthesiol 2012; 62: 46873.

8. Lee SI, Lee JH, Lee SC, Lee JM, Lee JH. Calcium and neostigmine antagonize gentamicin, but augment clindamycin-induced tetanic fade in rat phrenic nerve-hemidiaphragm preparations. J Anesth 2008; 22: 385-90.

9. Bruckner J, Thomas KC Jr, Bikhazi GB, Foldes FF. Neuromuscular drug interactions of clinical importance. Anesth Analg 1980; 59: 678-82.

10. Martyn JA. Neuromuscular physiology and pharmacology. In: Miller's Anesthesia. 7th ed. Edited by Miller DR: Philadelphia, Churchill Livingstone Elsevier. 2010, pp 344-53.

11. Bowman WC, Webb SN. Tetanic fade during partial transmission failure produced by non-depolarizing neuromuscular blocking drugs in the cat. Clin Exp Pharmacol Physiol 1976; 3: 545-55.

12. Zucker RS. Calcium and transmitter release. J Physiol Paris 1993; 87: 25-36.

13. Viby-Mogensen J. Neuromuscular monitoring. In: Miller's Anesthesia. 7th ed. Edited by Miller DR: Philadelphia, Churchill Livingstone Elsevier. 2010, pp 1516-7.

14. Elmqvist D, Quastel DM. A quantitative study of end-plate potentials in isolated human muscle. J Physiol 1965; 178: 505-29.

15. Neher E, Steinbach JH. Local anaesthetics transiently block currents through single acetylcholine-receptor channels. J Physiol 1978; 277: 153-76. 
16. de Oliveira MJ, Oliveira AC. Mechanisms underlying the vecuronium-induced tetanic fade in the isolated rat muscle. Pharmacol Toxicol 1999; 85: 282-7.

17. Gentry CL, Lukas RJ. Local anesthetics noncompetitively inhibit function of four distinct nicotinic acetylcholine receptor subtypes. J Pharmacol Exp Ther 2001; 299: 1038-48.

18. Fujii T, Masai M, Misawa H, Okuda T, Takada-Takatori Y, Moriwaki $\mathrm{Y}$, et al. Acetylcholine synthesis and release in NIH3T3 cells coexpressing the high-affinity choline transporter and choline acetyltransferase. J Neurosci Res 2009; 87: 3024-32.

19. Taivainen T, Meretoja OA, Rosenberg PH. The effect of epidural bupivacaine on vecuronium-induced neuromuscular blockade in children. Acta Anaesthesiol Scand 1994; 38: 453-6.

20. al Ahdal O, Bevan DR. Clindamycin-induced neuromuscular blockade. Can J Anaesth 1995; 42: 614-7.

21. Singh YN, Harvey AL, Marshall IG. Antibiotic-induced paralysis of the mouse phrenic nerve-hemidiaphragm preparation, and reversibility by calcium and by neostigmine. Anesthesiology 1978; 48: 418-24.

22. Caputy AJ, Kim YI, Sanders DB. The neuromuscular blocking effects of therapeutic concentrations of various antibiotics on normal rat skeletal muscle: a quantitative comparison. J Pharmacol Exp Ther $1981 ; 217: 369-78$.

23. Dotan ZA, Hana R, Simon D, Geva D, Pfeffermann RA, Ezri T. The effect of vecuronium is enhanced by a large rather than a modest dose of gentamicin as compared with no preoperative gentamicin. Anesth Analg 2003; 96: 750-4.

24. Liu C, Hu F. Investigation on the mechanism of exacerbation of myasthenia gravis by aminoglycoside antibiotics in mouse model. J Huazhong Univ Sci Technolog Med Sci 2005; 25: 294-6.

25. Chou TC. Theoretical basis, experimental design, and computerized simulation of synergism and antagonism in drug combination studies. Pharmacol Rev 2006; 58: 621-81.

26. Myers DR, DeFehr J, Bennet WM, Porter GA, Olsen GD. Gentamicin binding to serum and plasma proteins. Clin Pharmacol Ther 1978; 23: 356-60.

27. Kays MB, White RL, Gatti G, Gambertoglio JG. Ex vivo protein binding of clindamycin in sera with normal and elevated alpha 1-acid glycoprotein concentrations. Pharmacotherapy 1992; 12: 50-5.

28. Emanuelsson BM, Zaric D, Nydahl PA, Axelsson KH. Pharmacokinetics of ropivacaine and bupivacaine during 21 hours of continuous epidural infusion in healthy male volunteers. Anesth Analg 1995; 81: 1163-8.

29. McKenzie DK, Butler JE, Gandevia SC. Respiratory muscle function and activation in chronic obstructive pulmonary disease. J Appl Physiol 2009; 107: 621-9.

30. Pavlin EG, Holle RH, Schoene RB. Recovery of airway protection compared with ventilation in humans after paralysis with curare. Anesthesiology 1989; 70: 381-5. 